Short Research Communication

\title{
Preventing and Treating Hypoxia: Using a Physiology Simulator to Demonstrate the Value of Pre-Oxygena- tion and the Futility of Hyperventilation
}

Anna A. Lerant ${ }^{\circledR}{ }^{\bowtie}$, Robert L. Hester ${ }^{1}$, Thomas G. Coleman ${ }^{1}$, William J. Phillips², Jeffrey D. Orledge ${ }^{3}$, W. Bosseau Murray ${ }^{4}$

1. Department of Physiology and Biophysics, University of Mississippi Medical Center, University of Mississippi Medical Center, MS

2. Department of Anaesthesiology, Cleveland Clinic, Cleveland, OH, USA

3. Department of Emergency Medicine, University of Mississippi Medical Center, University of Mississippi Medical Center, MS, USA

4. Clinical Simulation Centre, Pennsylvania State University College of Medicine, Hershey, PA, USA

$\square$ Corresponding author: ANNA A. LERANT, MD, Department of Anaesthesiology, University of Mississippi Medical Center, University of Mississippi Medical Center, 2500 N. State Street Jackson, MS 39216-4505. Phone: 601-815-7485; FAX: 601-815-9182; Email: alerant@umc.edu

() 2015 Ivyspring International Publisher. Reproduction is permitted for personal, noncommercial use, provided that the article is in whole, unmodified, and properly cited. See http:/ /ivyspring.com/terms for terms and conditions.

Received: 2015.03.09; Accepted: 2015.07.07; Published: 2015.07.23

\begin{abstract}
Introduction: Insufficient pre-oxygenation before emergency intubation, and hyperventilation after intubation are mistakes that are frequently observed in and outside the operating room, in clinical practice and in simulation exercises. Physiological parameters, as appearing on standard patient monitors, do not alert to the deleterious effects of low oxygen saturation on coronary perfusion, or that of low carbon dioxide concentrations on cerebral perfusion. We suggest the use of HumMod, a computer-based human physiology simulator, to demonstrate beneficial physiological responses to pre-oxygenation and the futility of excessive minute ventilation after intubation.

Methods: We programmed HumMod, to A.) compare varying times (0-7 minutes) of pre-oxygenation on oxygen saturation $\left(\mathrm{SpO}_{2}\right)$ during subsequent apnoea; $\mathrm{B}$.) simulate hyperventilation after apnoea. We compared the effect of different minute ventilation rates on $\mathrm{SpO}_{2}$, acid-base status, cerebral perfusion and other haemodynamic parameters.

Results: A.) With no pre-oxygenation, starting $\mathrm{SpO}_{2}$ dropped from $98 \%$ to $90 \%$ in 52 seconds with apnoea. At the other extreme, following full pre-oxygenation with $100 \% \mathrm{O}_{2}$ for 3 minutes or more, the $\mathrm{SpO}_{2}$ remained $100 \%$ for 7.75 minutes during apnoea, and dropped to $90 \%$ after another 75 seconds. B.) Hyperventilation, did not result in more rapid normalization of $\mathrm{SpO}_{2}$, irrespective of the level of minute ventilation. However, hyperventilation did cause significant decreases in cerebral blood flow (CBF).

Conclusions: HumMod accurately simulates the physiological responses compared to published human studies of pre-oxygenation and varying post intubation minute ventilations, and it can be used over wider ranges of parameters than available in human studies and therefore available in the literature.
\end{abstract}

Key words: simulation, preoxygenation, hyperventilation, intubation, resuscitation

\section{Introduction}

Two errors by learners using high fidelity ("robotic") human simulator scenarios in airway and ventilatory management outside the operating room setting are often observed especially during simulated airway emergencies, where the crisis event includes low saturations.[1] Prior to intubation, pre-oxygenation (also called "denitrogenation") is often inadequately performed, or even totally omitted.[2] After intubation, during the subsequent manual ventilation, studies indicate that participants tend to hyperventi- 
late the simulated patient at rapid respiratory rates with large tidal volumes: firstly, as an aid to confirm equal and bilateral breath sounds, and secondly, in an attempt to more rapidly improve the saturation. [1;3] These two errors are also frequently observed in clinical practice during emergency intubations performed outside of the operating room or in the pre-hospital setting.[4]

Trainees are frequently not even aware of the deleterious effects (e.g. hyperventilation causing a decrease of cerebral perfusion) of these errors, because similar to clinical practice, the majority of robotic simulators cannot provide a real-time display of $\mathrm{H}^{+}$concentrations, alveolar $\mathrm{O}_{2}, \mathrm{~N}_{2}$ and $\mathrm{CO}_{2}$ concentrations, nor of cerebral perfusion. Additionally, this is a physiologically unstable phase and the end-tidal $\mathrm{CO}_{2}$ concentrations $\left(\mathrm{EtCO}_{2}\right)$ may not reflect the actual $\mathrm{CO}_{2}$ concentrations of various tissue compartments which are rapidly changing (e.g. central nervous system, CNS). Currently, there are no robotic simulator displays indicating cerebral blood flow (CBF).

Similar to the experience in simulation, inconsistent pre-oxygenation and excessive hyperventilation are also frequently present in clinical practice, especially outside the operating room, during "codes" or in the pre-hospital setting.[1-3] A recent retrospective, observational study of in situ pediatric mock codes in a hospital ward setting indicated that hyperventilation was present in every mock code reviewed.[1] The mean rates of ventilation by all providers, in all scenarios were about 2-5 times higher[1] than specified by Advanced Cardiovascular and Pediatric Life Support (ACLS and PALS) guidelines [5] It is possible that the practice demonstrated during simulation is both a reflection of what is being observed and learned in clinical practice, as well as an anxiety-driven response to the respiratory emergency at hand.

In daily clinical practice it is difficult to identify and/or quantify hyperventilation used as a method to more rapidly improve oxygenation ("get more oxygen into the patient"). This is because video recordings of clinical emergencies ("codes") are rare, and medical records usually do not include either the duration of pre-oxygenation, nor of the manual ventilatory rates and/or minute ventilations immediately after intubation. Therefore, even clinicians with much experience with "codes" do not necessarily have "experience" with the deleterious effects of hyperventilation on CBF.

As a method of enabling hands-on, experiential learning, we propose the hands-on use of screen based (computer based) training, using programs running mathematically modelled human physiology. As an example, we present a variety of simulation studies using a screen-based physiological simulator, HumMod (Version number 2.0.66, HC Simulation, LLC, http:/ / hummod.org). The HumMod physiology simulator operates with more than 7,500 variables and parameters,[6;7] of which we only present a few in this paper. This simulator can be used to expeditiously demonstrate a large number of combinations of variables to demonstrate the value of adequate pre-oxygenation as well as the futility and ineffectiveness of post-intubation hyperventilation to enhance oxygenation. The accuracy of the HumMod physiological model has been demonstrated in several studies.[7-9]

Our aim in this study is to use HumMod to demonstrate the deleterious effects of poorly performed pre-oxygenation, as well as the futility of post-intubation hyperventilation to more rapidly improve saturation. Using this simulation modality, it is possible to present data and parameters (such as cerebral blood flow - CBF) that cannot be demonstrated either in the clinical setting, or in the presently available simulator settings using robotic simulators.

\section{Methods}

\section{HumMod Experiments}

To establish a stable baseline for our studies, we used steady-state initial conditions in HumMod (Version number 2.0.66, HC Simulation, LLC, http://hummod.org), with a healthy, 30-year-old 75 $\mathrm{kg}$ male as the simulated patient with a tidal volume of $450 \mathrm{ml}$, basal respiratory rate of 11, and a dead space of $151 \mathrm{ml}$. This results in a minute ventilation of $5.0 \mathrm{~L} / \mathrm{min}$ and an alveolar ventilation of $3.3 \mathrm{~L} / \mathrm{min}$. Baseline arterial blood $\mathrm{pH}$ was 7.45. Partial pressures of arterial $\mathrm{O}_{2}\left(\mathrm{PaO}_{2}\right)$ and arterial $\mathrm{CO}_{2}\left(\mathrm{PaCO}_{2}\right)$ were 94 $\mathrm{mmHg}$ and $37 \mathrm{mmHg}$, respectively. For data collection for these simulations, the time interval between data points was 15 seconds.

\section{Duration of pre-oxygenation or de-nitrogenation: effects on the onset of hypoxia during apnoea}

For the first set of experiments, to study the effects of pre-oxygenation before apnoea, the simulated patient was set to breathe spontaneously with a tidal volume of $450 \mathrm{~mL}$ at 11 breaths/min with an inspired $\mathrm{O}_{2}$ percentage of $100 \%$ for $0,0.5,1,3,5$ and 7 minutes. Thereafter, to simulate apnoea, the ventilatory rate was set to zero. The experiment ended when the simulation indicated that a $\mathrm{PaO}_{2}$ of $30 \mathrm{mmHg}$ had been reached. While the program actually calculates and stores 7,500 parameters, for this first set of experiments we collected $\mathrm{O}_{2}$ saturation $\left(\mathrm{SpO}_{2}\right)$, cerebral blood flow, $(\mathrm{CBF})$, heart rate, mean arterial blood 
pressure, $\mathrm{PaO}_{2}, \mathrm{PaCO}_{2}$, and $\mathrm{pH}$ data at 15 second intervals.

\section{Hyperventilation: effects on SpO2 and cerebral blood flow}

For the second set of experiments, we used the same healthy, 30-year-old $75 \mathrm{~kg}$ male as the simulated patient with a tidal volume of $450 \mathrm{ml}$, basal respiratory rate of 11, and a dead space of $151 \mathrm{ml}$ as before. First, we created a stable, hypoxic, baseline state as follows:

The simulated patient was set to breathe spontaneously for 5 minutes at a rate of 11 breaths/minute at an inspired $\mathrm{O}_{2}$ percentage of $100 \%$. The tidal volume was model driven, and was $450 \mathrm{ml}$ per breath, giving a typical minute ventilation of $5 \mathrm{~L} / \mathrm{min}$. After 5

A

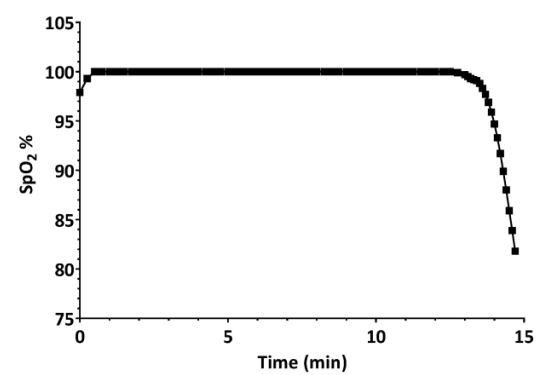

B

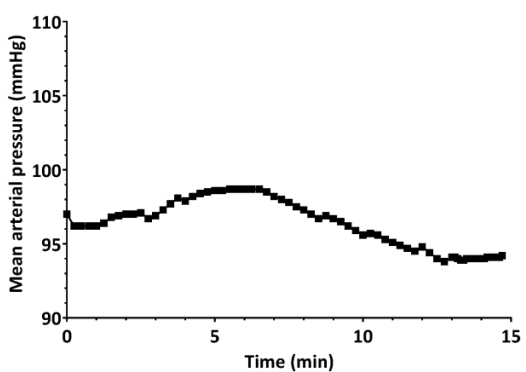

C

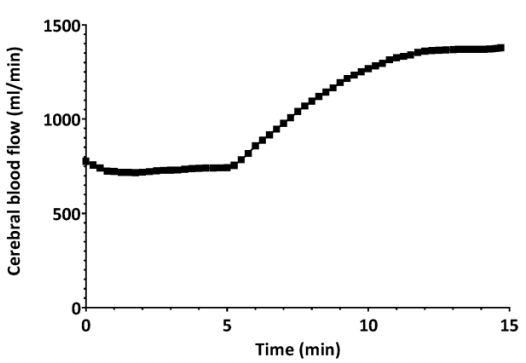

minutes, to simulate apnoea, the simulated patient's respiratory rate was set to zero as would be expected to occur during difficult intubation efforts, resulting in apnoea. The simulation was stopped when the $\mathrm{SpO}_{2}$ decreased to $80 \%$. At that point (9.8 minutes), the simulation was stopped and all physiological parameters were saved. This set of parameters served as a baseline for the second set of simulations (i.e. hyperventilation scenarios). The oxygen saturation, $\mathrm{CBF}$, heart rate, mean arterial pressure, arterial $\mathrm{O}_{2}$ and $\mathrm{CO}_{2}$ partial pressures as well as arterial blood $\mathrm{pH}$ during the apnoeic period are shown in Figure 1. The values at the 9.8 min point in Figure 1 represent our stable, baseline, hypoxic patient, which we used for the next set of experiments.

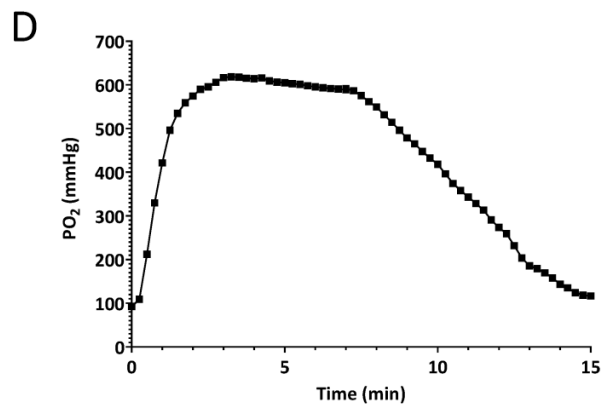

$E$

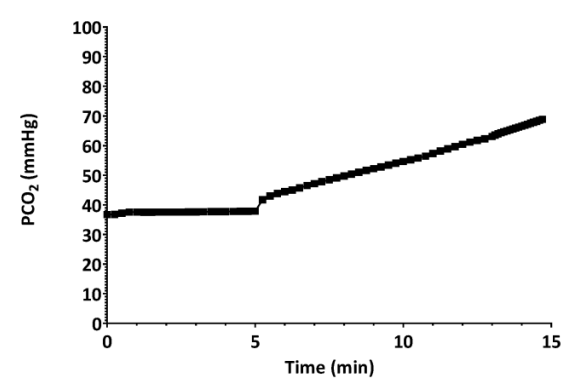

$\mathrm{F}$

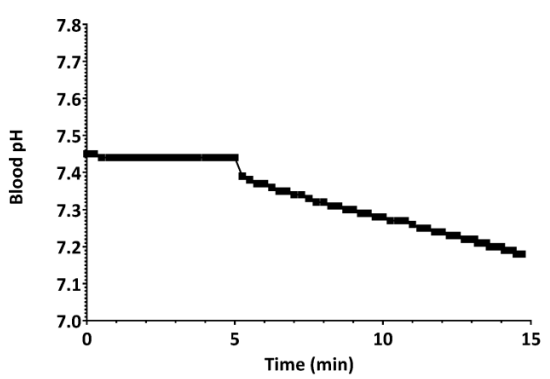

Figure 1: Effects of 5-min pre-oxygenation and subsequent apnoea to establish a "baseline" patient for the hyperventilation experiments. A) oxygen saturation $\left.\left(\mathrm{SpO}_{2}\right), \mathrm{B}\right)$ mean arterial pressure (MAP), C) cerebral blood flow, D) arterial partial $\mathrm{O}_{2}$ pressure $\left(\mathrm{PaO}_{2}\right)$, E) arterial partial $\mathrm{CO}_{2}$ pressure $\left(\mathrm{PaCO}_{2}\right) \mathbf{F}$ ) arterial blood $\mathrm{pH}$. The simulated patient was set to breathe spontaneously for 5 minutes at a rate of 11 breaths/minute at an inspired $\mathrm{O}_{2}$ percentage of $100 \%$. At 5 minutes, to simulate apnoea, the simulated patient's respiratory rate was set to zero. The simulation was stopped when the $\mathrm{SpO}_{2}$ decreased to $80 \%$ to simulate a desaturation episode. At that point the simulation was stopped and all physiological parameters were saved. 
Starting from this saved baseline state at the $\mathrm{SpO}_{2}$ of $80 \%$, the simulated patient was ventilated with $100 \%$ oxygen at a constant tidal volume of 450 $\mathrm{ml}$, and increasing respiratory rates of $5,10,20,30$, and 40 breaths/minute. This simulated, and enabled comparison of, the effects of hypoventilation, normal ventilation, and hyperventilation on the return to normal values, of the $\mathrm{SpO}_{2}$ and changes on other parameters, such as the cerebral blood flow. The simulation was stopped after 20 minutes at each respiratory rate. All reported parameters were saved at 15 sec intervals.

\section{Data analysis and presentation}

From HumMod software, the data were downloaded as comma delimited files into Excel spreadsheets (Office 2013, Microsoft Corporation, Redmond, WA). Data then were copied into Prizm (Version 6.05, GraphPad Software, La Jolla, CA) and graphs were produced.

\section{Results}

\section{Duration of pre-oxygenation: effects on $\mathrm{SpO} 2$ during subsequent apnoea}

The results of the pre-oxygenation experiment are summarized in Figures 2 and 3. The effects of various durations of pre-oxygenation are shown in the first section of each line in the graph. Apnoea started at the indicated time periods for each line on the graph. Pre-oxygenation had a clinically relevant effect on increasing the duration of apnoea before desaturation occurred (Figure 2A). With no pre-oxygenation, $\mathrm{SpO}_{2}$ started at $98 \%$, it dropped to $95 \%$ in 30 seconds and to $90 \%$ in an additional 20 seconds (Figure 2A). With pre-oxygenation for $3 \mathrm{~min}, \mathrm{SpO}_{2}$ started at $100 \%$, remained at $100 \%$ for 7 minutes (420 seconds), dropped to $95 \%$ after 30 additional seconds, and reached $90 \%$ after another 20 seconds (Figure 2A). A plateau effect of pre-oxygenation was reached by $3 \mathrm{~min}$.: this is shown by the time to the start of the decrease of $\mathrm{SpO}_{2}$ that was quite similar at 5 and $7 \mathrm{~min}$ of pre-oxygenation. A critical key physiologic learning point demonstrated was that once $\mathrm{SpO}_{2}$ started to decrease, the rate of change was rapid, irrespective of the duration of pre-oxygenation. (Figure 2A).

Delays in changes in haemodynamic parameters during apnoea correlated with the length of pre-oxygenation (Figures $2 \mathrm{~B}$ and $\mathrm{C}$ ).

Figure 3 demonstrates the effects of pre-oxygenation on arterial $\mathrm{PaO}_{2}, \mathrm{PaCO}_{2}$ and $\mathrm{pH}$ during apnoea. Pre-oxygenation is associated with a delay in $\mathrm{CO}_{2}$ accumulation and subsequent acidosis.
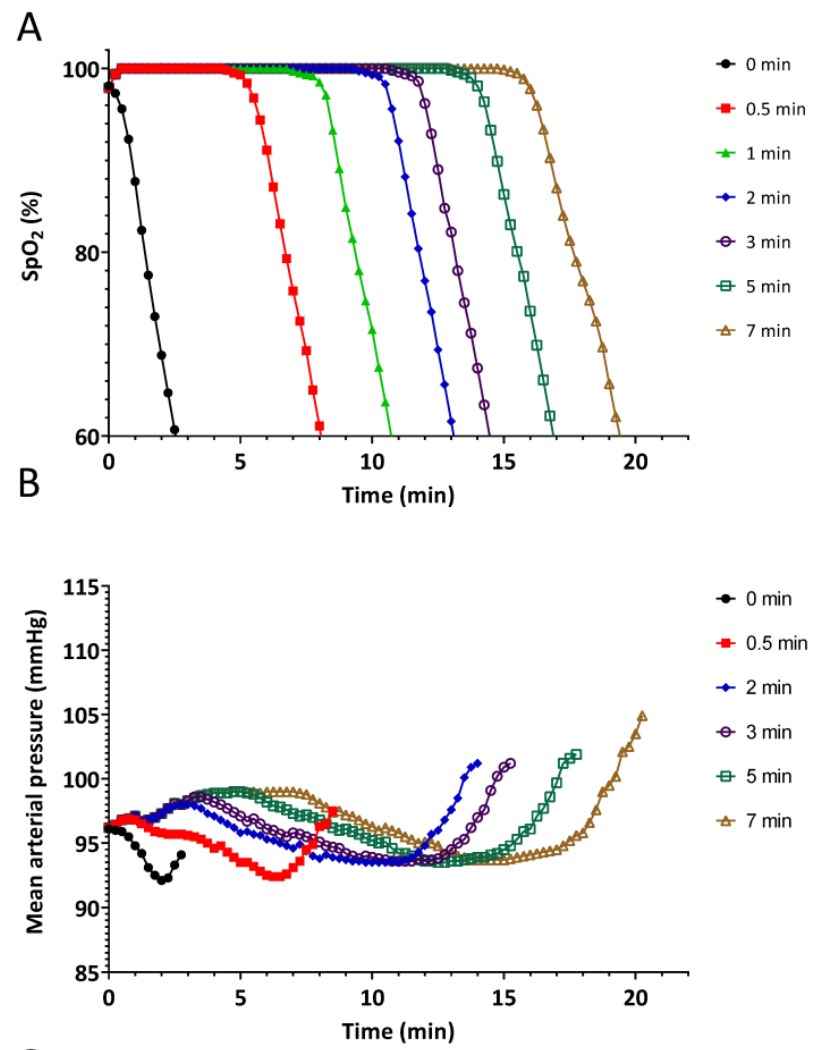

C

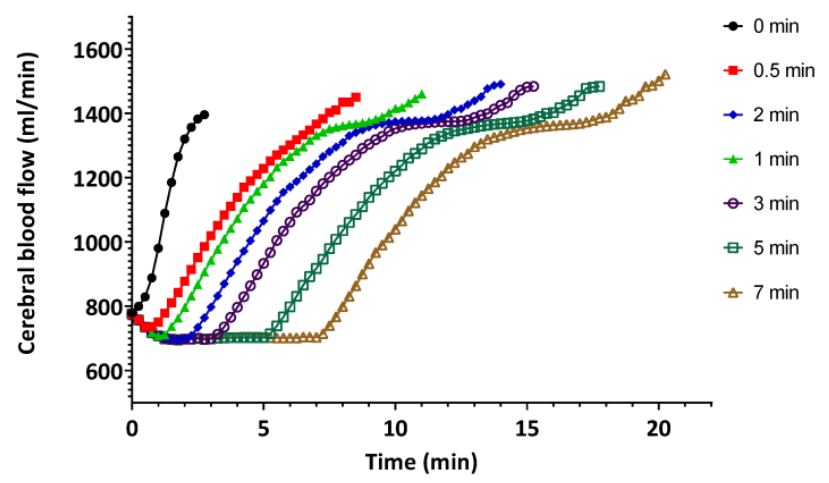

Figure 2: Effects of different durations of pre-oxygenation on A.) oxygen saturation $\left(\mathrm{SpO}_{2}\right)$, B.) mean blood pressure and $\mathrm{C}$.) cerebral blood flow during apnoea. Solid black line with circles indicates no pre-oxygenation on room air. During the pre-oxygenation time $0.5-7 \mathrm{~min}$ the simulated patient was set to breathe $450 \mathrm{~mL} / \mathrm{min}$ spontaneously at 11 breaths/minute with inspired oxygen of $100 \%$ for different durations.

\section{Hyperventilation: effects on recovery of $\mathrm{SpO} 2$ and cerebral blood flow}

The results of the hyperventilation simulation experiment are summarized in Figures 4-6. Oxygen saturation increased from the baseline reading of $80 \%$ and reached $98 \%$ within 60 seconds for each of the ventilatory rates (Figure $4 \mathrm{~A}$ and Figure 5), indicating no benefit of increased ventilatory rates, (or increased minute ventilation) on the recovery to an adequate level of oxygenation. In our simulation experiments, hyperventilation (due to increased respiratory rates 
with normal tidal volumes) had minimal effects on mean arterial pressure (Figure 4B), thereby not alerting clinicians to potential problems. Figure $4 \mathrm{C}$ shows the cerebral blood flow values, which are increased at baseline (due to hypoxia and auto-regulation), thereupon decrease rapidly correlating with $\mathrm{PaCO}_{2}$.

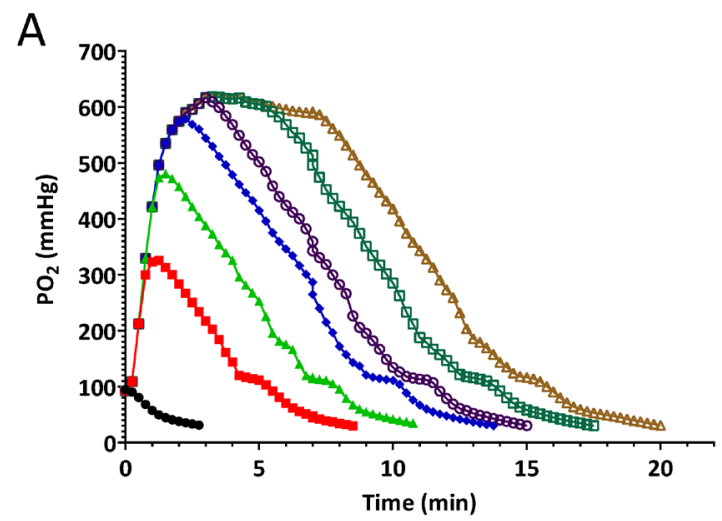

$\rightarrow 0$ min

$=0.5 \mathrm{~min}$

$\pm 1 \mathrm{~min}$

$\leftarrow 2$ min

$\ominus 3 \mathrm{~min}$

๑ $5 \mathrm{~min}$

$\triangle 7 \mathrm{~min}$

B

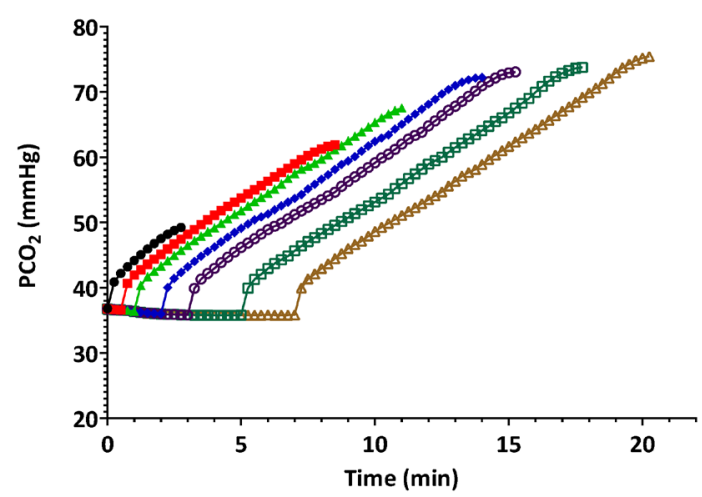

C

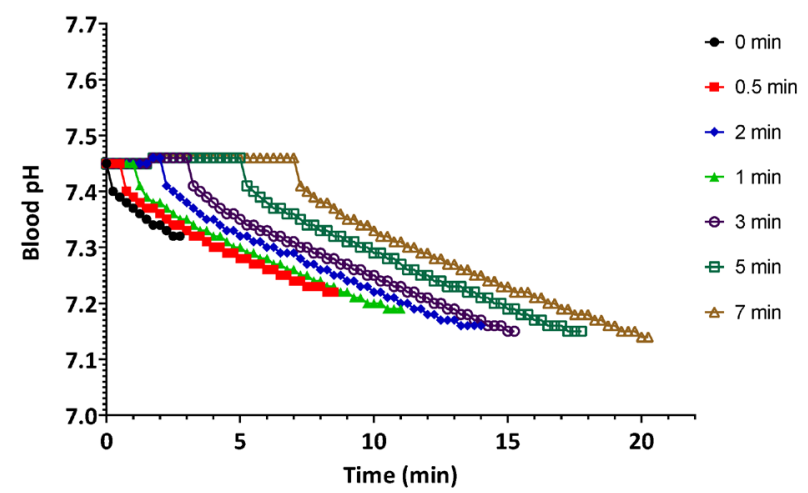

Figure 3: Effects of different durations of pre-oxygenation on A.) arterial $\mathrm{O}_{2}$ partial pressure $\left(\mathrm{PaO}_{2}\right)$, B.) arterial $\mathrm{CO}_{2}$ partial pressure $\left(\mathrm{PaCO}_{2}\right)$, and C.) arterial $\mathrm{pH}$ during apnoea. Solid black line with squares indicates no pre-oxygenation on room air. During the pre-oxygenation time 0.5-7 min the simulated patient was set to breathe $450 \mathrm{~mL} / \mathrm{min}$ spontaneously at 11 breaths/minute with inspired oxygen of $100 \%$ for different durations.
Our simulated results indicate that over $20 \mathrm{~min}, \mathrm{~Pa}$ $\mathrm{CO}_{2}$ increased from $70 \mathrm{mmHg}$ to $80 \mathrm{mmHg}$ at a ventilation rate of 5 breaths/min, while hyperventilation at 40 breaths/min decreased $\mathrm{PaCO}_{2}$ to $30 \mathrm{mmHg}$ in 120 seconds (Figure 6B).

A
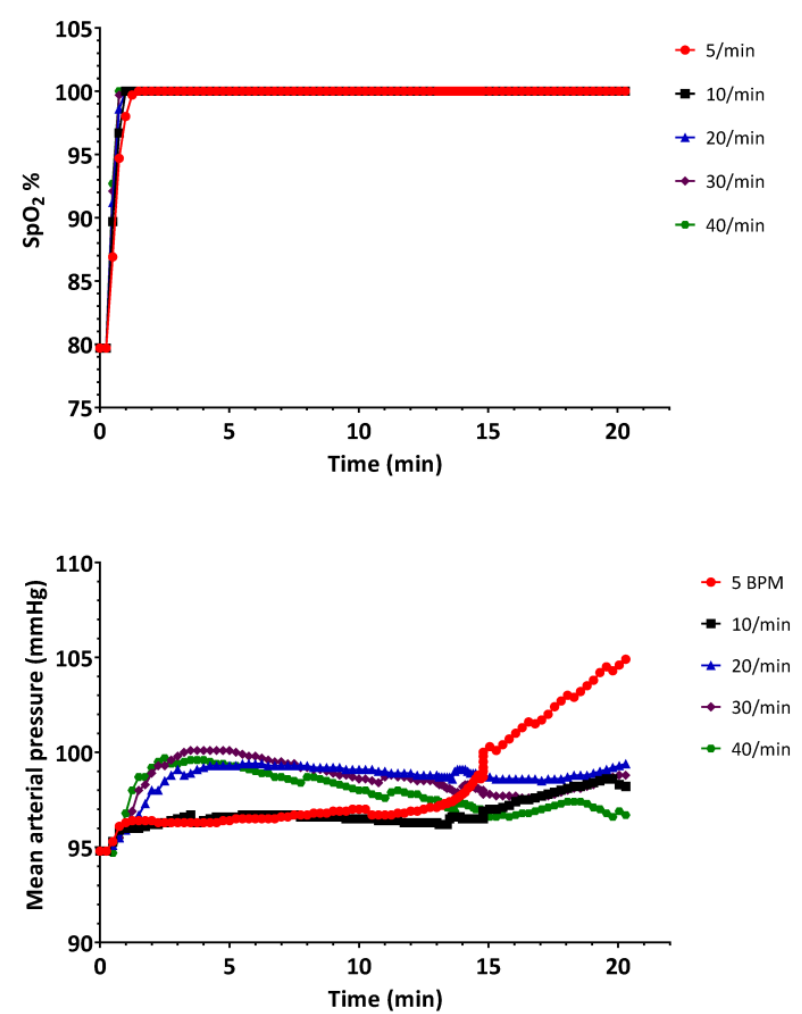

C

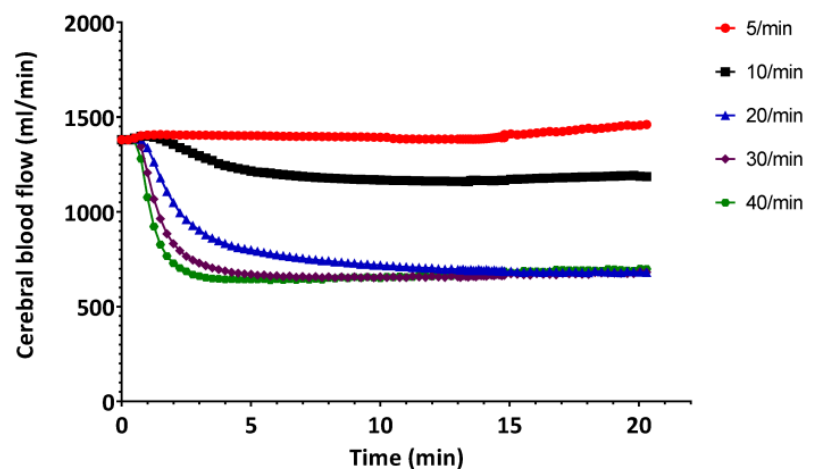

Figure 4: Changes in A.) oxygen saturation $\left(\mathrm{SpO}_{2}\right)$ B.) mean arterial pressure and C.) cerebral blood flow when the simulated patient was ventilated at different rates. Experiment was started from a state when the $\mathrm{SpO} 2$ was $80 \%$. 


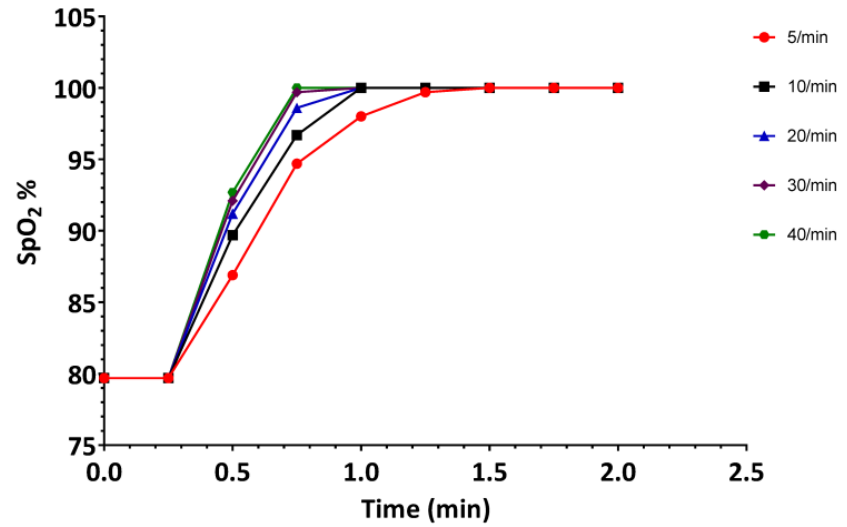

Figure 5: Changes in oxygen saturation $\left(\mathrm{SpO}_{2}\right)$ during the first 2 minutes when the simulated patient was ventilated at different rates. Experiment was started from a state when $\mathrm{SpO} 2$ was $80 \%$. Data are the same as in Figure 3A.

A
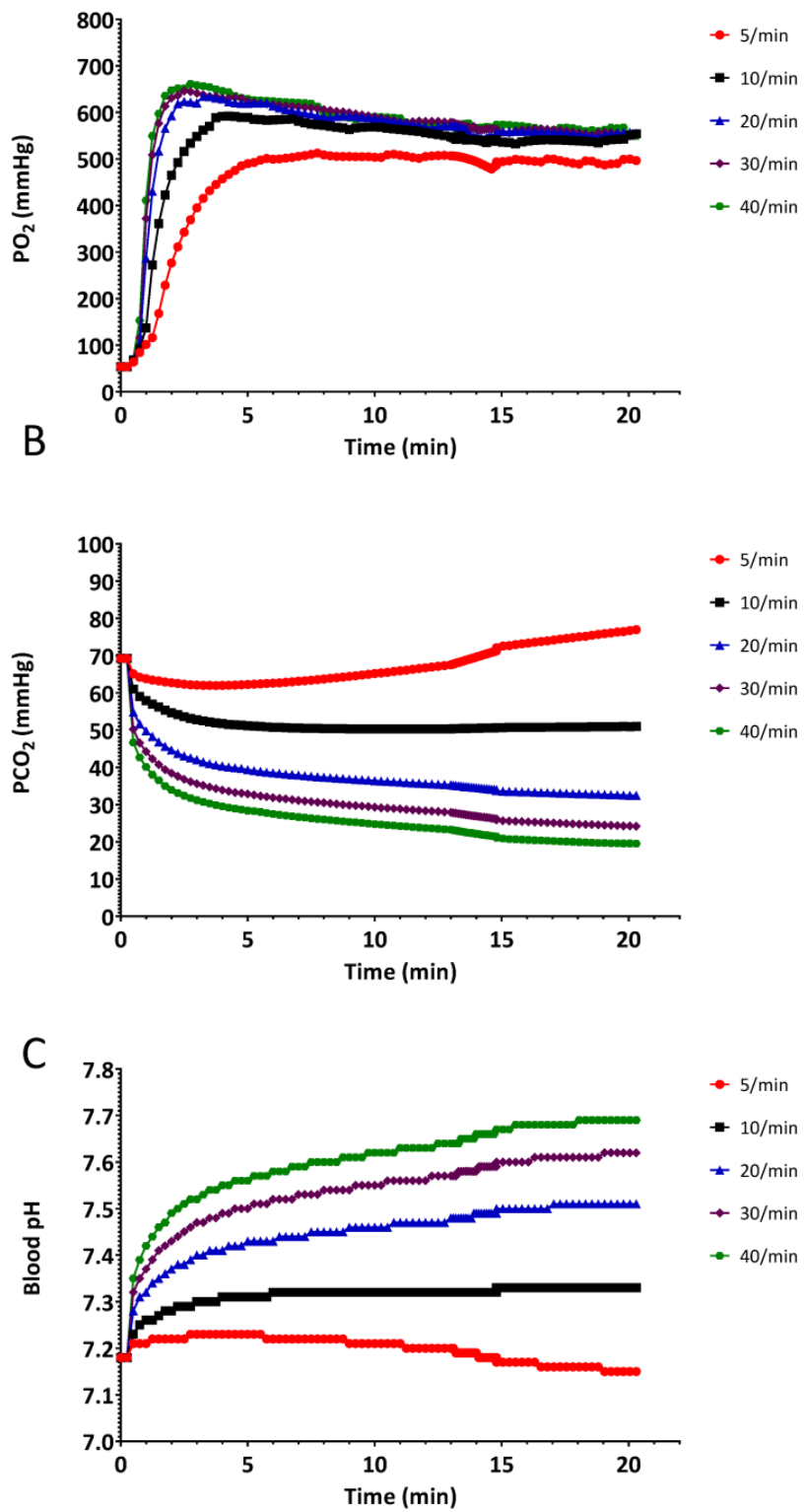

Figure 6: Changes in A.) arterial $\mathrm{O}_{2}$ partial pressure $\left(\mathrm{PaO}_{2}\right)$, B.) arterial $\mathrm{CO}_{2}$ partial pressure $\left(\mathrm{PaCO}_{2}\right)$, and $\mathrm{C}$.) arterial $\mathrm{pH}$, when the simulated patient was ventilated at different rates. Experiment was started from a baseline state when $\mathrm{SpO} 2$ was $80 \%$.

\section{Discussion}

Our study strongly supports the ACLS recommendation to avoid hyperventilation. Our data indicate that oxygen saturation does not increase faster if hyperventilation is instituted, and that normal ventilation is a physiologically superior technique with less deleterious effects on the cerebral blood flow.

When a large proportion of trainees exhibit the same behavior in simulation (such as poor pre-oxygenation and post-intubation hyperventilation), it is possible that this is a reflection of their learning and clinical practice.

To promote an improvement in clinical practice, an experiential, hands-on learning session might prove to be more useful than a didactic platform ("lecture"). This is especially important when dealing with a complex task which includes several learning domains. For instance, the trainees: 1.) have to acquire the knowledge ("facts") as well as understand and apply the knowledge; 2.) have to have the psycho-motor skills to perform the task; 3 .) have to have the willingness and attitude to want to change their behavior.

Trainees have been correctly taught that hypoventilation and an increased $\mathrm{CO}_{2}$ concentration are bad for a traumatized brain (with loss of auto-regulation of $\mathrm{CBF}$ ) as it further increases the intra-cranial pressure. Trainees therefore have a tendency to hyperventilate all patients. We therefore present the cerebral blood flow graphic in Figure 1C deliberately to demonstrate to trainees that, with normal autoregulation, cerebral perfusion INCREASES with an increase in $\mathrm{PaCO}_{2}$ concentration, and that the converse is also true - with NORMAL auto-regulation, a decrease in $\mathrm{PaCO}_{2}$ leads to a decreased cerebral perfusion, which can be deleterious. This use of HumMod clearly demonstrates the value of such a comprehensive modelled simulator. Similarly, the terminal increases in blood pressure in Figure $2 \mathrm{~B}$ due to hypoxia are demonstrated - this represents the "last-ditch" response of the sympathetic system when a critically low oxygen tension (around $40 \mathrm{mmHg}$ ) is reached. This pre-terminal increase in blood pressure is also seen in Figure 4B with the lowest respiratory rate of 5 breaths per minute.

Our results indicate that with the HumMod screen-based human physiology simulator, we were able to closely reproduce the effects of pre-oxygenation presented in other human studies.[10-12] The accuracy of the haemodynamic parameters of HumMod has also been validated, although in a different model.[9] We found a rapid decrease in saturation observed after 50 seconds with apnoea after breathing room air. This rapidity is due to the simulated patient in our model being apnoeic at 
functional residual capacity (FRC), rather than after a vital capacity inhalation,[13] as would be typical in breath hold diving. Furthermore, the typical pulse oxygen monitor presents a running average of the last 15 pulses on the screen,[14] which further delays the "observed" decrease in saturation in human studies. The mathematical model (HumMod) presents the "real time" saturation in the arterial blood, and it is therefore expected to present a more rapid decline in saturation. As an example, one of the first commercially available oxygen monitors in 1984 (prior to the concept of the running average) showed a decrease in saturation within the breath holding time of Navy divers.[15]

Clinical practice guidelines emphasize the importance of pre-oxygenation [16] as a key technique to increase the "safe" duration of apnoea without desaturation, which would allow more time for intubation. Pre-oxygenation ("denitrogenation") for 3-5 min at an inspired $\mathrm{O}_{2}$ percentage of $100 \%$, affords a safe $\mathrm{SpO}_{2}$ of $100 \%$ for $5-8$ minutes while the patient is apnoeic and endotracheal intubation is being performed. Trainees are typically unprepared for the rapid decrease in saturation, once it starts to decrease. This rapid decrease is due to the steepness of the haemoglobin-oxygen dissociation curve. Seeing it several times in succession in a physiologically based, validated simulator, with the ability and time to reflect on the experience, we believe would have a beneficial effect on learning and retention. This prepares the trainee for expecting, observing, and learning from such a rapid decrease in a patient. For example, during an acute crisis event, without prior preparation, the trainees are focused on performing tasks to manage the crisis: they tend to be overwhelmed [17], and learning is compromised.[18] Furthermore, after the crisis event, there is seldom time for debriefing and reflective learning.[19] The first three steps of the Kolb's Learning Cycle can be comprehensively addressed by the learning using the simulation program. This learning will prepare the trainees for the $4^{\text {th }}$ step, where the learner applies the new understandings in clinical practice. [19]

The 2010 Advanced Cardiovascular Life Support (ACLS) guidelines [5] strongly emphasize the importance of ventilatory rates of less than 8-10 breaths/min in adults, thereby avoiding the unwanted effects of hyperventilation and hypocarbia with the resulting decreased cerebral and intrathoracic blood flow. Unfortunately, these guidelines are frequently not followed during the excitement of resuscitation in emergency patient care settings, where hyperventilation is one of the most common mistakes made during resuscitation.[20] Another example of the deleterious effects of hyperventilation is the study by Aufderheide et al.[3] They found a mortality rate of $100 \%$ when an average percentage of time of inspiratory positive pressure of $47 \%$ was recorded in the lungs.[3] They also found in their study [3] that the patients were ventilated at rates of 30 breaths/min, and the average duration of each inspiration and exhalation was 1 second each.

Our study supports the ACLS recommendation to avoid hyperventilation. The effect of hyperventilation is difficult to appreciate on standard monitors used in the emergency setting, as well as in the anesthesia setting. Trainees and practitioners focus on the saturation: they are relieved when $\mathrm{SpO}_{2}$ is $100 \%$ before an intubation, or when the crisis period has been solved by placing the endotracheal tube. Since the hemodynamic effects of hyperventilation are not reflected by dramatic changes in heart rate and systemic blood pressure (see Figures $3 \mathrm{c}$ and $3 \mathrm{~d}$ ), the providers are typically unaware of the effects of hyperventilation on the physiology. Our observations, and published data obtained during high fidelity simulation mock codes,[1] both confirm that once $\mathrm{SpO}_{2}$ drops to $80 \%$, most health care providers tend to hyperventilate the patients with the "mistaken" concept that "more oxygen delivered faster into the lungs, is better." Robotic simulation using standard monitors does not seem to be effective to changing this behavior. However, model-driven simulators (robotic and/or flat screen) have the capability for the instructor to extract all the physiological variables from the model as an aid to teaching and understanding.

Hyperventilation has profound effects on the central and systemic circulations.[21;22] Experimental studies in pigs indicate that blood flow to the brain stem and cerebellum decreases soon after hyperventilation starts. Mechanical hyperventilation with low frequency and large tidal volumes decreases cardiac output and reduces the flow to most tissues, including the brain and coronary arteries.[3;23] If hyperventilation is induced by an increased frequency at normal tidal volumes, as in our simulation experimental setting, cardiac and cerebral blood flow decreases without major changes in cardiac output.[23]

Noting the short time courses of the changes in saturation, we believe it is important for simulation instructors to base the physiology in their simulation sessions on scientifically based, model driven data, rather than on their impressions, especially given the low incidence and infrequent opportunities to manage patients presenting with low FRCs (fever, pregnancy, obesity, etc.) where minimal pre-oxygenation occurred.[24] Since there is a lack of sophistication of existing physiologic monitoring capability outside of the OR and the ICU, few clinicians will have extensive experience with a controlled range of minute ventila- 
tions in patients with saturations of $80 \%$ after prolonged intubation attempts. Furthermore, during typical clinical cases existing standard monitors are not able to provide data on minute by minute estimations of $\mathrm{H}^{+}, \mathrm{PaCO}_{2}, \mathrm{CBF}$, etc. Therefore, simulation instructors can use such a physiologically based simulation program to generate "realistic" parameters when using a robotic simulator in an "instructor driven", override mode. We suggest the combined use of model driven, scientifically based programs to support and inform the development of instructor driven simulation scenarios.

Limitations to our study include: i) We could only study a small fraction of the available parameters in the model. For instance, PEEP/CPAP (positive end expiratory pressure and continuous positive airway pressure) would be expected to influence the results via affecting not only FRC, but also the shunt fraction, cardiac output, distribution of blood contained in each vascular bed, etc. This should be addressed in a future study, once PEEP and CPAP, and their effect on the shunt fraction, have been built into the model. ii) Apneic oxygenation, e.g. with a channel conducting oxygen (rather than being used as a suction channel) close to the glottis opening would also affect the results by effectively decreasing the anatomic dead space. In a future study, the minimum and optimal oxygen flow rates could be studied to provide guidance for the design and utilization of such equipment.[25]

Based on the demonstrated accuracy of the HumMod program, we propose that simulation instructors calibrate and validate their scenarios using physiology-based, mathematically modelled, simulation programs, such as HumMod.

We also believe that the ability of the mathematical simulation models to "look inside" the simulated patient will give the trainees a greater understanding of the value and need for pre-oxygenation, as well as the futility and dangers of hyperventilation during stressful circumstances. We believe such understanding might lead to a beneficial change in behaviors.

\section{Competing Interests}

The authors have declared that no competing interest exists.

\section{References}

1. Niebauer JM, White ML, Zinkan JL, Youngblood AQ, Tofil NM. Hyperventilation in pediatric resuscitation: performance in simulated pediatric medical emergencies. Pediatrics 2011; 128(5):e1195-e1200.

2. Gebremedhn EG, Mesele D, Aemero D, Alemu E. The incidence of oxygen desaturation during rapid sequence induction and intubation. World J Emerg Med 2014; 5(4):279-285.

3. Aufderheide TP, Lurie KG. Death by hyperventilation: a common and life-threatening problem during cardiopulmonary resuscitation. Crit Care Med 2004; 32(9 Suppl):S345-S351.
4. Park SO, Shin DH, Baek KJ, Hong DY, Kim EJ, Kim SC et al. A clinical observational study analysing the factors associated with hyperventilation during actual cardiopulmonary resuscitation in the emergency department. Resuscitation 2013; 84(3):298-303.

5. Neumar RW, Otto CW, Link MS, Kronick SL, Shuster M, Callaway CW et al. Part 8: adult advanced cardiovascular life support: 2010 American Heart Association Guidelines for Cardiopulmonary Resuscitation and Emergency Cardiovascular Care. Circulation 2010; 122(18 Suppl 3):S729-S767.

6. Abram SR, Hodnett BL, Summers RL, Coleman TG, Hester RL. Quantitative Circulatory Physiology: an integrative mathematical model of human physiology for medical education. Adv Physiol Educ 2007; 31(2):202-210.

7. Hester RL, Brown AJ, Husband L, Iliescu R, Pruett D, Summers R et al. HumMod: A Modeling Environment for the Simulation of Integrative Human Physiology. Front Physiol 2011; 2:article12.

8. Summers RL. Computer simulation studies and the scientific method. J Appl Anim Welf Sci 1998; 1(2):119-131.

9. Summers RL, Ward KR, Witten T, Convertino VA, Ryan KL, Coleman TG et al. Validation of a computational platform for the analysis of the physiologic mechanisms of a human experimental model of hemorrhage. Resuscitation 2009; 80(12):1405-1410.

10. Benumof JL, Dagg R, Benumof R. Critical hemoglobin desaturation will occur before return to an unparalyzed state following $1 \mathrm{mg} / \mathrm{kg}$ intravenous succinylcholine. Anesthesiology 1997; 87(4):979-982.

11. Stewart IB, Bulmer AC, Sharman JE, Ridgway L. Arterial oxygen desaturation kinetics during apnea. Med Sci Sports Exerc 2005; 37(11):1871-1876.

12. Tanoubi I, Drolet $P$, Donati F. Optimizing preoxygenation in adults. Can J Anaesth 2009; 56(6):449-466.

13. Villars PS, Kanusky JT, Levitzky MG. Functional residual capacity: the human windbag. AANA J 2002; 70(5):399-407.

14. Vagedes J, Poets CF, Dietz K. Averaging time, desaturation level, duration and extent. Arch Dis Child Fetal Neonatal Ed 2013; 98(3):F265-F266.

15. Foster P, Murray W, Schneeberger J, Howell L. Oxygen saturation during breath-holding, Pulse Oximetry. In: Payne J, Severinghaus J, editors. London: Springer Verlag. 1986: 143-150.

16. Weingart SD, Levitan RM. Preoxygenation and prevention of desaturation during emergency airway management. Ann Emerg Med 2012; 59(3):165-175.

17. Yerkes RM, Dodson JD. The Relation of Strength of Stimulus to Rapidity of Habit-Formation. Journal of Comparative Neurology and Psychology 1908; 18:459-482.

18. Mackenzie CS, Wiprzycka UJ, Hasher L, Goldstein D. Associations between psychological distress, learning, and memory in spouse caregivers of older adults. J Gerontol B Psychol Sci Soc Sci 2009; 64(6):742-746.

19. Schultz K, McEwen L, Griffiths J. Applying Kolb's Learning Cycle to Competency-Based Residency Education. Acad Med 2014.

20. O'Neill JF, Deakin CD. Do we hyperventilate cardiac arrest patients? Resuscitation 2007; 73(1):82-85

21. Inglesby TV, Costin JC, Hanley HG, Berry PE, Skinner NS, Jr. Reflex regulation of peripheral blood flow during lung hyperinflation. Am J Cardiol 1972; 29(5):650-658.

22. Pitts S, Kellermann AL. Hyperventilation during cardiac arrest. Lancet 2004; 364(9431):313-315.

23. Karlsson T, Stjernstrom EL, Stjernstrom H, Norlen K, Wiklund L. Central and regional blood flow during hyperventilation. An experimental study in the pig. Acta Anaesthesiol Scand 1994; 38(2):180-186.

24. Langeron $\mathrm{O}$, Birenbaum A, Le SF, Raux M. Airway management in obese patient. Minerva Anestesiol 2014; 80(3):382-392.

25. Boedeker BH, Bernhagen M, Miller DJ, Murray WB. User preference comparing a conventional videolaryngoscope blade vs. a novel suction videolaryngoscope blade in simulated hemorrhagic airway intubation. Stud Health Technol Inform 2012; 173:72-74. 